RAFAEL SECO SARAVALLI

\title{
DOGMÁTICA JURÍDICA E REGRAS TÉCNICAS
}

Dissertação de Mestrado

Orientador: Professor Associado Dr. Juliano Souza de Albuquerque Maranhão

UNIVERSIDADE DE SÃO PAULO

FACULDADE DE DIREITO

São Paulo - SP

2020 



\section{RAFAEL SECO SARAVALLI}

\section{DOGMÁTICA JURÍDICA E REGRAS TÉCNICAS}

Dissertação apresentada à Banca Examinadora do Programa de Pós-Graduação em Direito, da Faculdade de Direito da Universidade de São Paulo, como exigência parcial para obtenção do título de Mestre em Direito, na área de concentração de Filosofia e Teoria Geral do Direito, sob a orientação do Professor Associado Doutor Juliano Souza de Albuquerque Maranhão.

\section{UNIVERSIDADE DE SÃO PAULO}

FACULDADE DE DIREITO

São Paulo - SP 


\section{Serviço de Processos Técnicos da Biblioteca da}

Faculdade de Direito da Universidade de São Paulo

Saravalli, Rafael Seco

Dogmática Jurídica e Regras Técnicas/ Rafael Seco Saravalli. -- São Paulo, 2020.

147 p. ; $30 \mathrm{~cm}$.

Dissertação (Mestrado) - Programa de Pós-Graduação em Direito, Faculdade de Direito, Universidade de São Paulo, São Paulo, 2020.

Orientador: Maranhão, Juliano Souza de Albuquerque.

1.Regras técnicas. 2. Dogmática jurídica. 3. Teoria do direito. 4. Positivismo jurídico. 5. Proposição normativa. I. Maranhão, Juliano Souza de Albuquerque orient. II. Título. 
SARAVALLI, Rafael Seco. Dogmática jurídica e regras técnicas. 2020. $147 \mathrm{f}$. Dissertação (Mestrado) - Faculdade de Direito, Universidade de São Paulo, São Paulo, 2020.

Dissertação apresentada à Banca Examinadora do Programa de Pós-Graduação em Direito, da Faculdade de Direito da Universidade de São Paulo, como exigência parcial para obtenção do título de Mestre em Direito, na área de concentração de Filosofia e Teoria Geral do Direito, sob a orientação do Professor Associado Doutor Juliano Souza de Albuquerque Maranhão.

Aprovado em:

\section{Banca Examinadora}

Prof. Dr. Instituição:

Julgamento: Assinatura:

Prof. Dr. Instituição:

Julgamento: Assinatura:

Prof. Dr. Instituição: Assinatura: 

Iuris prudentia est divinarum atque humanarum rerum notitia, iusti atque iniusti scientia. (Ulpiano, Dig. 1.1.10.2)

Iuri operam daturum prius nosse oportet, unde nomen iuris descendat. est autem a iustitia appellatum: nam, ut eleganter celsus definit, ius est ars boni et aequi. (Ulpiano, Inst. Dig. 1,1,1pr) 



\section{AGRADECIMENTOS}

Agradeço ao Professor Juliano Maranhão, pela oportunidade de desenvolvimento acadêmico-científico que estes anos de convívio proporcionaram. Mas, além disso, agradeço também o incansável exercício de ensino e divulgação de tema tão esquecido na tradição jurídica brasileira: lógica aplicada ao direito.

Agradeço aos professores Rafael Mafei e Edélcio Gonçalves, que participaram da minha qualificação de mestrado e, por meio da pergunta correta, delimitaram o caminho adequado desta dissertação.

Agradeço à minha mãe e a meus irmãos, por terem me dado suporte quando precisei. Também agradeço à minha sogra e meu sogro, por nos terem ajudado nestes anos.

Agradeço aos colegas de trabalho da Procuradoria Geral da USP, por terem compreendido e me ajudado nas minhas ausências. Em especial destaque, agradeço ao amigo Mauricio Montané Comin, quem me substituiu em diversas situações e "segurou as pontas" quando foi necessário.

Agradeço aos colegas de Lawgorithm, na figura do Marco Almada, pelas conversas e pelo entusiasmo na promoção do conhecimento sobre inteligência artificial aplicada ao direito.

Por último e mais importante, agradeço à minha esposa, Isabel, que me apoiou e, mais do que isso, me suportou durante este período difícil. Compartilhar a vida com você, Isabel, é motivo de alegria constante e fonte de inspiração para criar e aceitar novos desafios. Suas palavras de estímulo tornaram possível a realização deste trabalho, que só não lhe é dedicado por não ser digno de tal mister. 



\section{RESUMO}

SARAVALLI, Rafael Seco. Dogmática jurídica e regras técnicas. 2020. $147 \mathrm{f}$. Dissertação (Mestrado) - Faculdade de Direito, Universidade de São Paulo, São Paulo, 2020.

Este estudo investiga a regra técnica como um tipo de norma que representa uma função pragmática da dogmática jurídica: a de responder "como" se cumpre o direito. Para apresentar este tipo de norma e a possibilidade de representação desta função da dogmática, a discussão foi localizada na tradição positivista, o que nos forçou a comparar a regra técnica com outra função: a de responder "quais" normas fazem parte do direito . Inicialmente, procuramos compreender o significado de dogmática e a importância de suas funções na constituição de seu sentido. Dentre uma de suas funções, destacamos a de dar respostas acerca de normas. Após, escolhemos dois tipos de perguntas para se investigar: "qual" e "como". O último tipo representa a função das regras técnicas. As perguntas e respostas "qual", por sua vez, são analisadas como funções representadas pela proposição normativa. Como exemplos presentes da teoria do direito de proposições normativas, investigamos a proposição jurídica de Alf Ross. Investiga-se também uma teoria em que cada uma destas funções não está clara, a Rechtssatz de Hans Kelsen. A Rechtssatz surge como um bom exemplo da necessidade de se tratar de forma distinta cada qual destas funções. Ao analisar as regras técnicas, encontramos seus antecedentes na literatura jurídica. Sua função de mediação entre linguagem da realidade e linguagem das normas. As condições de sucesso das respostas às perguntas "como" são analisadas em suas faces da executabilidade e proibição de lacuna normativas. Também se analisa a possibilidade de as regras técnicas representarem perguntas e respostas "como" de forma desengajadas, sem vinculação moral. São apresentados argumentos favoráveis a esta possibilidade. Concluímos sobre a necessidade de distinção entre estas duas funções e a necessidade de distintas perguntas para se tratar da posição antirreducionista do direito. Por fim, apresentamos a relação existente entre os diferentes sentidos de ciência normativa do direito e as perguntas "qual" e "como".

Palavras-chave: Regras técnicas. Dogmática jurídica. Teoria do Direito. Positivismo jurídico. Proposição normativa. 



\begin{abstract}
SARAVALLI, Rafael Seco. Legal dogmatic and technical oughts. 2020. 147 f. Dissertation (Master) - Law School University of São Paulo, São Paulo, 2020.

This study investigates technical oughts as a type of norm which represents a pragmatic function of legal dogmatics: answering how someone fulfil the law. In order to present this type of norm and the possibility of representing this function, the debate is addressed to the positivistic tradition, which compelled us to compare technical oughts with another function: answering which norms belong to the law. Firstly, we sought to understand the meaning of legal dogmatic and the importance of its functions for the constitution of its meaning. Among its functions, we highlighted giving answers about norms. Afterwards, we chose two types of questions to investigate: which and how. The last type represents the function of the technical oughts. The which questions and answers are analyzed as functions represented by normative proposition. As an example of normative propositions we presented Alf Ross's legal proposition. We also investigated Hans Kelsen's Rechtssatz as a good example of confusion between different types of questions and the need to distinguish them. As we anlysed the technical oughts, we found their antecedents in the legal literature and its role of mediating the language of reality and the language of norms. We studied the conditions for successfully answering "how" questions, specially the executability and the absence of normative gaps. We also examined the technical oughts as how questions and answers without moral attachment. We concluded on the need to distinguish between these two functions and the need for more than one type of question to represent positivist anti-reductionist position. Finally, we presented the relation between how and which questions and the different meanings of legal normative science.
\end{abstract}

Keywords: Technical oughts. Legal dogmatic. Theory of law. Legal positivism. Normative proposition. 



\section{SUMÁRIO}

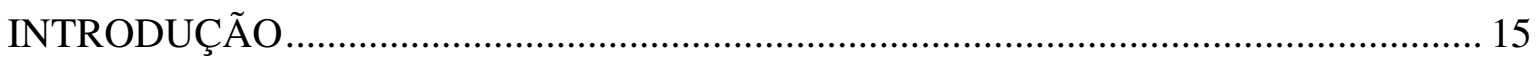

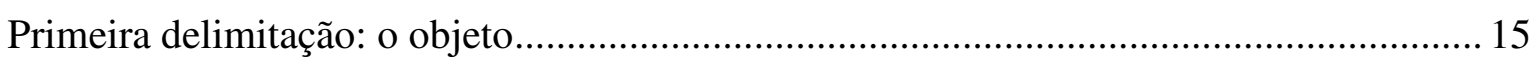

Segunda delimitação: do nível da análise à tradição teórica .............................................. 17

Terceira delimitação: método e "do que esta dissertação não trata" e "do que trata esta

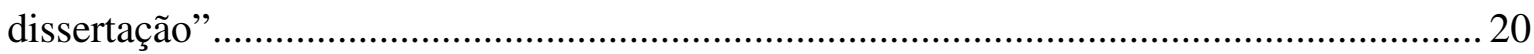

CAPÍtUlo I - PROCURANDO NOSSAS PERGUNTAS E RESPOSTAS ....................................... 23

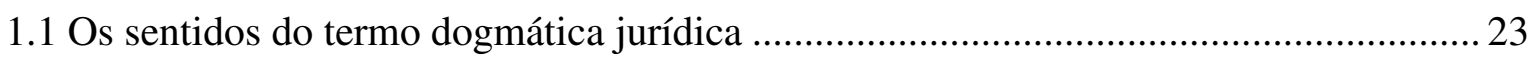

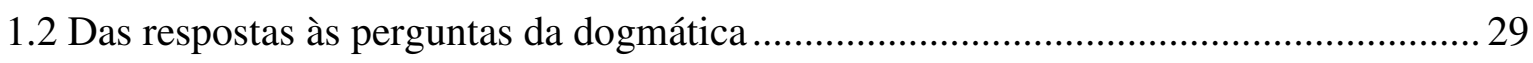

1.3 As perguntas e respostas da dogmática: a visão da teoria do direito positivista ............ 35

CAPÍTULO II - PROPOSIÇÕES NORMATIVAS: SUAS PERGUNTAS E RESPOSTAS ......................... 46

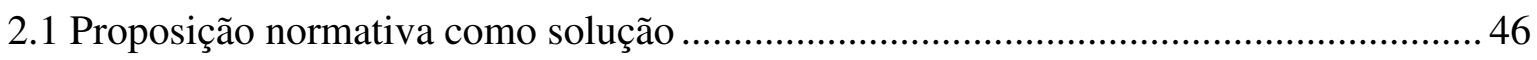

2.2 Das proposições jurídicas de Ross...................................................................... 55

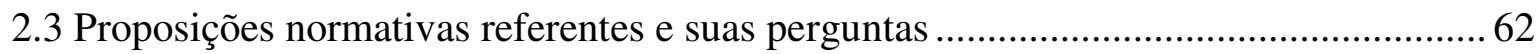

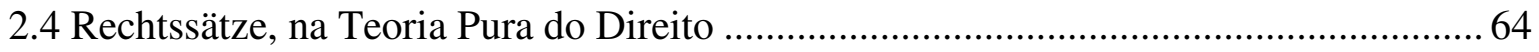

2.5 A reabilitação da Rechssatz da TPD: Raz e as sentenças descompromissadas

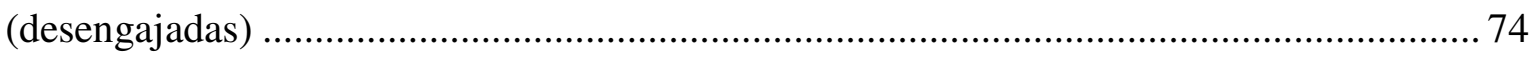

2.6 Entre Bulygin e Raz: as perguntas e respostas na Rechtssatz ................................... 79

CAPÍTULO III - NORMAS E REGRAS TÉCNICAS: IDENTIFICANDO AS PERGUNTAS E

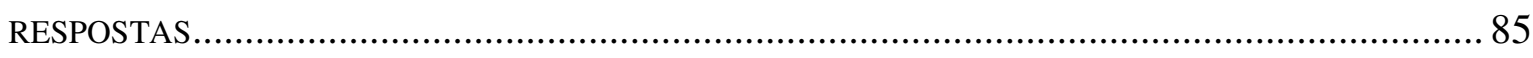

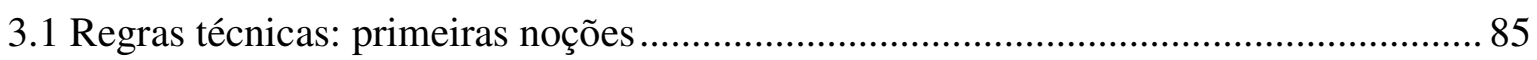

3.2 Juristas e regras técnicas: primeiras perguntas ......................................................... 92 
3.3 Regra técnica como uma resposta da dogmática...

3.4 Mediação entre Linguagem da Norma e Linguagem Real: Regras Técnicas. 100

3.5 O legislador racional: perguntas e respostas. 107

3.6 Boas respostas: a executabilidade como coerência do legislador racional. 109

3.7 Boas perguntas: as lacunas ......

3.8 Censor e Expositor nas regras técnicas

CONCLUSÕES

4.1 Reducionismo e antirredionismo e diferentes perguntas à dogmática jurídica 133

$4.2 \mathrm{O}$ sucesso das respostas "qual" e "como" e a necessidade compreender cada peculiaridade

4.3 Ciências normativas: dos conjuntos de normas ao sistema normativo. 135

4.4 Limitações desta dissertação, trabalhos futuros e as marcas da dogmática. 137

BIBLIOGRAFIA 140 


\section{INTRODUÇÃO}

Quando ainda era um aluno da Graduação de Direito, uma frase me chamou a atenção. Foi a tradução de Millor Fernandes da fala de um dos coveiros da peça Hamlet de Shakespeare, que disse:

"Ora, senhor, a pele dele está tão curtida pela profissão..."

A partir desta afirmação, comecei a me indagar quais marcas o trabalho com o direito poderia imprimir sobre nós. Na época, não tinha a informação para dar uma resposta ou a maturidade para sequer entender a pergunta. Hoje, bem mais velho, já consigo observar algumas marcas físicas em mim e em diversos colegas. São as lombalgias, o leve sobrepeso, gastrites, típicas marcas de um trabalho estressante. Mas mais do que isso, temos marcas mais profundas que nos identificam como advogados, juízes, promotores etc. Digo as marcas de uma maneira de pensar própria, cujos atributos não são fáceis de enumerar. Quais seriam, então, estas marcas mais profundas, e como compreendê-las? Hoje, apesar do tempo, confesso não ter ainda a sabedoria necessária para responder esta pergunta. Mas acredito que procurar entender o discurso da dogmática jurídica, em suas diversas dimensões, pode talvez ser uma maneira inicial de entendimento. Longe de querer dar qualquer resposta, esta dissertação é um exercício de compreensão desta pergunta.

Evidentemente, este trabalho não pretende uma análise de toda a dogmática jurídica, mas tão somente de uma de suas funções: a de dar alguns tipos de respostas específicas. Mesmo este escopo pode ganhar contornos amplos se pensarmos que, essencialmente, o que o discurso da dogmática jurídica faz é dar respostas. Por isso, antes de tudo, devemos delimitá-lo, para bem especificar o tema deste trabalho.

\section{Primeira delimitação: o objeto}

O tema principal da dissertação é a possibilidade de regras técnicas exercerem uma função específica da dogmática jurídica: a de dar respostas. Quem, primeiramente, notou a peculiaridade das regras técnicas foi Von Wright, definindo-as como tipos de normas que condicionam um fim específico à realização de certas ações. Podemos citar como exemplos deste tipo de regras, as seguintes orações: "Para tornar a casa habitável, você precisa ligar o aquecedor", "Para perder peso, é preciso comer menos", "Para 
respeitar seu país, você deve cumprir as ordens proferidas pelo Presidente.”. Observa-se que é apresentado um fim: "tornar a casa habitável...", "perder peso", "respeitar seu país"; e também se indica uma ação necessária a se atingir este fim, respectivamente: "ligar o aquecedor", "comer menos" e "cumprir as ordens proferidas pelo Presidente".

$\mathrm{Na}$ literatura jurídica, poucos autores procuraram estudar as regras técnicas como uma forte candidata a uma proposição jurídica da ciência do direito, destacando Aarnio $^{1}$, Maranhão ${ }^{2}$ e Rodriguez ${ }^{3}$. Enquanto o primeiro as descarta, ante aspectos criativos e avaliativos da dogmática jurídica, os outros dois as assumem como uma proposta interessante para compreender alguns aspectos da ciência direito. Maranhão, especialmente, a utiliza para compreender as questões teóricas enfrentadas na Rechtssatz (proposição jurídica) de Kelsen.

A dogmática jurídica, contudo, não é termo que sempre é coincidente com uma ciência do direito. Como veremos no capítulo I, há alguns sentidos em que se pode entender os termos ciências do direito e também dogmática jurídica. Todavia, mais importante do que se compreender o sentido preciso dos termos é entender os problemas com os quais se pretende conviver.

Por esta razão, delimitamos os problemas abordados nesta dissertação à capacidade de se dar respostas satisfatórias sobre o direito, mas não adentraremos na questão teórica referente às condições de verdade e hierarquias de resposta. Neste sentido, não se analisam todos aspectos do tema associado às proposições jurídicas, mas nos perguntamos somente: como conseguimos responder a perguntas "como se cumpre o direito?" ou "quais normas fazem parte do direito?".

Com esta delimitação, o que se pretende é tratar de funções específicas de “qualquer dogmática”, isto é, qualquer sentido que conferimos à dogmática do direito, posto que é função tanto de uma ciência do direito, em sentido estrito, como do "discurso dos profissionais jurídicos" responder questões sobre o direito. Por isso, em alguns momentos, o termo dogmática se aproximará mais do sentido de uma ciência do direito; noutros, de um discurso faticamente presente na sociedade. Mas como se verá ao longo da

\footnotetext{
${ }^{1}$ AARNIO, A. The rational as reasonable, D. Reidel Publishing Company 1987.

${ }^{2}$ MARANHÃO, JULIANO. Padrões de racionalidade na sistematização de normas, Tese de Doutorado defendida para obtenção de grau de Doutor, junto à Faculdade de Direito da Universidade São Paulo, em 2004. MARANHÃO, JULIANO. Positivismo jurídico lógico-inclusivo, São Paulo: Marcial Pons, 2012. MARANHÃO, JULIANO. Estudos sobre Lógica e Direito. São Paulo : Marcial Pons, 2013.

${ }^{3}$ RODRIGUEZ, JORGE LUIS. "Norms, Truth, and Legal Statements". Jordi Ferrer Beltran Jose Juan Moreso y Diego Papayanis (eds.), Neutralityan Theory of Law. Editora: The Netherlands, Springer, 2013, p. 127-146.
} 
dissertação, majoritariamente serão tratados de problemas atrelados a uma dogmáticaciência do direito.

Agora, como abordar este objeto? Recentemente, temos diversos tipos de estudos sobre o direito - sociológicos, analítico, normativo, descritivo -, qual deles será escolhido?

\section{Segunda delimitação: do nível da análise à tradição teórica}

Este trabalho é voltado para uma abordagem analítica da dogmática jurídica. Portanto, não se trata de um estudo empírico, mas conceitual, no âmbito do que tradicionalmente se denomina de teoria do direito. Algumas qualificações, contudo, fazemse necessárias. A primeira delas se refere ao que chamamos de "nível da análise".

No texto Sein and Sollen in legal Science, ${ }^{4}$ Bobbio observou diferentes "níveis" nos quais o tema da normatividade no e do direito pode ser tratado. Teríamos um primeiro cujo objeto são as normas de um dado ordenamento jurídico, em sentido amplo. Seria a própria ciência do direito, ou dogmática jurídica, à qual ele dá o nome de Jurizprudenz. Já o discurso que tem por objeto a própria Jurisprudenz é o da teoria do direito, ou Metajurisprudenz. Neste nível se investiga as proposições da Jurisprudenz, seus pressupostos e sua relação com o ordenamento. Já no nível mais abstrato, as condições de sucesso de uma teoria do direito são analisadas e a própria teoria (ou teorias) do direito são compreendidas em suas possibilidades e implicações. Este nível seria o da Metametajurisprudenz.

No nível da Metajurisprudenz, esta dissertação investiga a resposta jurídica como figura teórica que representa o caráter lógico-linguístico da dogmática jurídica. Não se busca, portanto, investigar problemas de uma Metametajurisprudenz, tal qual a questão da neutralidade valorativa ser uma condição de sucesso de uma teoria do direito ${ }^{5}$. Posto desta forma, sendo a Jurisprudenz o objeto de nossos problemas, uma tomada de posição é necessária.

$\mathrm{Na}$ atual evolução da literatura jurídica, falar em "a” teoria do direito pode ser um erro. As diversas matrizes filosóficas, concepções linguísticas e propósitos nos dão diversas teorias do direito. Assim, para os propósitos e limites do presente trabalho, a

${ }^{4}$ BOBBIO, NORBERTO. "Sein" and "Sollen" in the legal Science.' Archiv für Rechts - und Sozialphilosophie LVI, nº 6, pp 7-30, 1970.

${ }^{5}$ MARANHÃ̃, JULIANO. Positivismo jurídico lógico-inclusivo. São Paulo: Marcial Pons, 2012, p. 24. 
escolha de uma tradição jurídica para se analisar possíveis funções de uma Jurisprudenz é diretriz necessária. É neste sentido que, neste trabalho, partiremos dos propósitos e premissas metodológicas positivistas.

Das diversas premissas e argumentos positivistas, um bom ponto de partida se encontra na análise da linguagem da ciência jurídica proposta por Bentham:

XXI. Jurisprudence is a fictitious entity: nor can any meaning be found for the word, but by placing it in company with some word that shall be significative of a real entity. To know what is meant by jurisprudence, we must know, for example, what is meant by a book of jurisprudence. A book of jurisprudence can have but one or the other of two objects: 1. To ascertain what the law is: 2. to ascertain what it ought to be. In the former case it may be styled a book of expository jurisprudence; in the latter, a book of censorial jurisprudence: or, in other words, a book on the art of legislation ${ }^{6}$. (g.n.)

Neste trecho, Bentham formula o principal postulado da teoria do direito positivista: a necessária distinção entre o direito como ele é, competência do Expositor, do direito como ele deve ser, missão de um Censor. A despeito do caráter desta proposta ${ }^{7}$, é importante ressaltar duas possíveis leituras deste preceito metodológico da teoria do direito (Metajurisprudenz): uma positiva e outra negativa. A positiva diz ser necessária a fundamentação de uma ciência do direito em algum tipo de descrição do fenômeno jurídico. A negativa diz que uma ciência do direito para ser considerada racional não deve se engajar na defesa de posições normativas. Na leitura negativa, mais do que falar o que a ciência do direito deve ser, diz o que ela não deve ser. Independentemente da leitura, é fácil perceber que não só a natureza do fenômeno jurídico, mas a própria limitação das proposições da ciência do direito torna-se questão importante no debate jurídicopositivista.

\footnotetext{
${ }^{6}$ BENTHAM, JEREMY. An introduction to the Principles of Morals and Legislation. Batoche Books, 2000, p 234.

BUSTAMANTE, a partir da leitura de Postema da obra de Bentham, defende o caráter normativo do positivismo benthaniano. Nesta leitura, a cisão entre direito "como é" do direito como "deve ser" surge como uma necessidade prático-teorética a qual permite estabelecer uma maior segurança jurídica, bem como a contraposição com a censorial jurisprudence, que permitiria estabelecer um juízo crítico, fundamentado no preceito da utilidade sobre o direito (BUSTAMANTE, THOMAS. "A breve história do positivismo descritivo. O que resta do positivismo jurídico depois de H. L. A. Hart? " em Revista Novos Estudos Jurídicos - Eletrônica, Vol. 20 - n. 1 - jan-abr 2015, pp. 307-327.) Independente do real caráter da proposta benthaniana, importa ressaltar para a presente dissertação o reflexo em uma teoria do direito positivista e, na consequente, proposta de ciência do direito.
} 
Além deste preceito metodológico mais geral, há também outras teses positivistas, com caráter tanto conceitual quanto metodológico. Raz delimitou duas teses presentes em autores positivistas. São elas: a tese da separação do direito e moral e a tese das fontes. A primeira defende a ausência de conexão necessária entre o conteúdo do direito e de preceitos morais. Já a segunda defende o caráter social, empírico do fenômeno jurídico.

Somando-se a estas premissas, as teorias do direito positivistas podem ter dois vieses: um reducionista, informando que os enunciados jurídicos, para se manterem fiéis à cientificidade, devem ser reduzidos a proposições descritivas (leitura positiva); e outro antirreducionista que, ante o caráter normativo do discurso jurídico, defende a necessidade de se tratar a normatividade específica do fenômeno jurídico, o que repercute também nas proposições sobre o direito.

É fácil perceber que, para os reducionistas (como Benthan, Austin e Ross, por exemplo), as teses da separação e das fontes, apesar de independentes, são facilmente harmonizadas com as condições de verdade de proposições descritivas. Isto é, sendo o direito reduzido à descrição de fatos, podemos distinguir fatos de preceitos morais (tese de separação) e inferir o direito a partir de fatos sociais (tese das fontes). A crítica que surge é de outro tipo: a utilidade desta ciência, a ausência do tratamento de aspecto relevante do fenômeno, etc... Já, para os antirreducionistas, não há a mesma facilidade para se determinar as características da proposição jurídica, mas se torna evidente que a ciência do direito representada possui uma função distinta da mera "apresentação" de objetos físicos empíricos.

Observamos, pois, com as teses reducionistas e antirreducionistas, que o que está em jogo é a representação de distintas funções de uma possível ciência do direito. Nesta dissertação, longe de se formular uma tese positivista, procuramos explorar em perguntas e respostas da dogmática jurídica duas distintas funções exercidas. Uma de responder "quais normas fazem parte do direito?" e outra de "como se cumpre o direito?". Como representantes destas duas funções, propusemos dois tipos distintos de enunciados, respectivamente: as proposições normativas e as regras técnicas. Como uma posição intermediária e problemática, investigaremos as Rechtssätze de Kelsen. Por se tratar de um estudo em nível de mestrado, procuramos delimitar bem os modelos teóricos apresentados, sendo escolhida como representante das proposições normativas a teoria rossiana dos enunciados científicos do direito. Já sobre as regras técnicas, nos ancoramos em Rodriguez, Maranhão e, principalmente, Von Wright. 


\section{Terceira delimitação: método e "do que esta dissertação não trata" e "do que trata esta dissertação"}

A escolha das regras técnicas como objeto de estudo nos obriga a enfrentar diversas consequências teóricas e metodológicas, e, mais do que explicar as razões para se investigar determinados temas, é pertinente a explicação do porquê não se investigou outros.

Primeiramente, as regras técnicas, por tratarem de assunto atinente às proposições da ciência do direito, atraem para o debate diversos temas. Dentre eles, destaco três de certa forma correlatos: o da interpretação jurídica, as condições de verdade das proposições da ciência do direito (objetividade), e, por último, as soluções das disputas teóricas do debate jurídico.

Quando trazemos estes temas para a dinâmica de perguntas e respostas, percebemos que não está em jogo a capacidade de sucesso de se responder adequadamente, mas a determinação de critérios para se escolher, entre diversas respostas (virtualmente possíveis), uma melhor. Tais temas possuem uma complexidade e literatura muito amplas, podendo tratar desde concepções sobre linguagem até noções de objetividade. Teríamos, por exemplo, que tratar da própria delimitação do significado do termo interpretação em autores como Marmor, a noção de norma e teoria das fontes dos realistas genoveses e, inevitavelmente, o debate metodológico Dworkin-Positivistas. Tais debates, por si só, escapam e muito do escopo de um mestrado, tornando a realização deste trabalho impossível. Por esta razão, trataremos somente da capacidade de sucesso das respostas. Como se verá, os temas mencionados aparecerão de forma coadjuvante ou quando forem necessários para se apresentar um argumento. Podemos, portanto, dizer que não se trata de uma dissertação sobre interpretação jurídica ou fundamento de uma dogmática científica (e prática) jurídica, apesar de poder servir de base para desenvolvimento futuro sobre estes temas.

O segundo motivo decorre da pouca literatura sobre as regras técnicas. Assim, apesar de se buscar a elaboração de um trabalho mais voltado para a análise bibliográfica jurídica - método mais adequado à uma dissertação de mestrado- , em alguns momentos, partiremos para argumentos presentes na história da lógica das normas. Este caráter dúplice pode ter limitado ou comprometido a exploração do tema. Contudo, como não se 
buscou qualquer formalismo desnecessário, bem como não se demandou conceitos estranhos ao debate jurídico, acredito que esta não trouxe prejuízo relevante.

Agora, procurando delimitar especificamente do que esta dissertação pretende tratar, vale a pena um breve resumo.

Dividimos o texto em três capítulos, com uma conclusão. O primeiro capítulo tem por objetivo compreender o papel da função pragmática da dogmática jurídica na determinação dos seus diversos sentidos. Dividiremos em dois sentidos distintos e "opostos" em que se compreende este termo: dogmática como ciência do direito e dogmática como fenômeno social. Entre estes dois "extremos", procuraremos estabelecer a função de dar respostas específicas sobre o direito como um bom ponto de partida de análise. Para tanto, procuraremos estabelecer dois tipos de perguntas sobre o direito: "qual" e "como". O primeiro demanda pelo conhecimento sobre quais normas fazem parte de determinado ordenamento e o segundo tipo requer os meios necessários ao cumprimento do direito. A partir destes dois tipos, procuraremos entender quais perguntas a teoria do direito positivista considera válidas para uma ciência do direito e, consequentemente, para representar as proposições jurídicas.

No segundo capítulo procuraremos investigar as perguntas "qual", a partir da figura teórica da proposição normativa. Esta é considerada como proposição que trata de descrever normas. Investigaremos, portanto, o significado da descrição de normas e alguns dos problemas a ela associados. Como paradigma de proposição normativa, na teoria do direito positivista (em sentido lato), investigaremos a proposição jurídica rossiana. Após, envidaremos esforços para compreender a teoria da proposição jurídica de Kelsen, a Rechtssatz. Ao final deste capítulo, teremos as dificuldades da tese antirreducionista, no quadro teórico do positivismo jurídico.

No terceiro capítulo, chegaremos ao objetivo deste trabalho: investigar as regras técnicas como tipo de normas aptas a responderem perguntas "como". A partir de uma investigação do conceito de regras técnicas, estabeleceremos uma classificação útil à representação de aspectos jurídicos. Exporemos algumas propostas de utilização deste tipo de norma para compreensão da dogmática jurídica. Após, trataremos da função da dogmática jurídica de responder perguntas do tipo "como" e sua relação com as regras técnicas. Veremos também o papel de mediação da regra técnica entre a linguagem real e a linguagem da norma. Mas para se realizar esta mediação, é preciso compreender as condições de sucesso das respostas "como", isto é, das regras técnicas. Investigaremos 
duas destas condições: a executabilidade e completude das respostas. Por fim, este capítulo investiga a relação das regras técnicas com a proposta metodológica positivista.

A partir destas análises, na conclusão, procuraremos contrapor os dois tipos de respostas, analisar as consequências teóricas de cada uma delas, bem como investigaremos relação entre estes dois tipos de funções exercidas pela dogmática jurídica. 


\section{CONCLUSÕES}

Neste capítulo, apresentamos quatro grupos distintos de conclusões. Um primeiro associado às teses do reducionismo e antirreducinismo e sua associação com diferentes funções da dogmática jurídica. Um segundo grupo trata dos padrões de sucesso das respostas "qual" e "como" e a necessidade de dissociação delas quando tratar das funções da dogmática jurídica. Um terceiro grupo, concluímos sobre o significado do termo ciência normativa, bem como a distinção entre conjunto de normas e sistema de normas e sua consequência para compreensão das funções da dogmática jurídica. Ao final, encerramos com as limitações do presente trabalho e trabalhos futuros.

Mas, antes, iremos sumarizar as principais conclusões presentes nos capítulos precedentes:

1.1 Quando investigamos o significado do termo "dogmática jurídica”, vimos dois sentidos distintos nos quais ele se encontra, o de dogmática-ciência, tratando de problemas metodológicos, e de dogmática-história, tratando do debate sobre esta instituição. Antes de definir um sentido, procuramos estabelecer a função de responder perguntas como um passo inicial para compreender o sentido de dogmática jurídica.

1.2 Para localizar as perguntas e respostas exercidas pela dogmática jurídica, procuramos compreender em qual tópico do debate metodológico este tema se insere. Notamos que, quando falamos de perguntas e respostas, estamos tratando de proposições da dogmática jurídica direito. Após, tentamos compreender as perguntas e respostas em um aspecto geral, procurando analisar quando uma resposta consegue realizar sua função pragmática com sucesso (isto é, responder). Destacamos dois tipos de perguntas sobre normas que se mostram interessantes para a representação da função pragmática da dogmática jurídica de responder perguntas: as perguntas sobre qual norma faz parte do direito (perguntas "qual) e as que indagam como se cumpre o direito (perguntas "como").

1.3 Com estes dois tipos de perguntas em mente, procuramos compreender que tipo de pergunta a tradição positivista aceita como própria de uma ciência do direito (dogmática-ciência). Vimos que apesar de haver uma adesão inicial a perguntas "qual", a posição antirreducionista traz um complicador, não sendo clara a função de uma ciência do direito positivista, para esta posição. Para explorar as funções (perguntas) que as posições reducionistas e antirreducionistas defendem, sugerimos as figuras teóricas da proposição normativa, a Rechtssatz de Kelsen e as regras técnicas. Também sugerimos uma leitura da 
proposta metodológica positivista, não fundamentada exclusivamente na descrição de normas. Mais especificamente, sugerimos uma leitura daquela proposta, com fundamento na distinção entre ciência do direito expositiva (expositor jurisprudence) e ciência do direito avaliativa (censorial juriprudence).

2.1 Analisamos a figura teórica da proposição normativa. Ela bem representa a capacidade de responder perguntas "qual", posto que indica ou descreve aspectos da norma: sua pertinência ao conjunto, sua eficácia, sua relação com outras normas etc. Contudo, a descrição de normas pode ter complicações, ante a eventualidade de representar padrões normativos $\underline{\text { da }}$ linguagem objeto, na metalinguagem. Diante desta dificuldade, nós sugerimos duas posturas: a cautelosa e a audaciosa. A primeira é representada pelas proposições normativas referentes, que incorporam poucos (ou nenhum) padrões do discurso normativo da linguagem objeto na metalinguagem. A segunda trata das proposições normativas reflexivas, que procuram refletir na metalinguagem padrões de da linguagem objeto. Como exemplos de cada uma delas no âmbito da teoria do direito, apresentamos a teoria rossiana da proposição jurídica e a Rechtssatz kelseniana.

2.2. Ao analisar as proposições jurídicas rossianas, vimos que as normas aparecem associadas à descrição de fatos empíricos, sem qualquer associação da linguagem das normas com a linguagem da ciência do direito. A normatividade do discurso do direito não é incorporada na ciência do direito, sendo esta um ramo da sociologia. A crítica que surge é da utilidade de uma ciência deste tipo.

2.3 Procuramos compreender os problemas colocados pela Rechtssatz. Para isso, analisamos duas leituras em sentidos distintos: a de Raz e a de Bulyigin. Após a compreensão dos argumentos de ambos, sugerimos que a proposta kelseniana confunde diferentes tipos de perguntas da ciência do direito. Há, na teoria kelseniana, a confusão entre fundamentação teórica de suas proposições e fundamentação obrigacional das normas. No lado das perguntas, parece tratar de perguntas "qual" e "devo agir...?". No lado das respostas, há a pretensão da teoria kelseniana de responder estas duas perguntas, com o mesmo enunciado.

2.4 A confusão presente na Rechtssatz nos força a compreender duas diferentes funções da dogmática jurídica de forma dissociada. As perguntas e respostas práticas, voltadas para ação, não podem ser confundidas com perguntas e respostas "qual”, cuja finalidade é ampliar o conhecimento sobre determinado conjunto de normas. Sugerem-se as regras técnicas como excelentes representantes desta função. 
3.1. Investigamos as regras técnicas como um tipo específico de norma que associa uma ação ao sucesso de se atingir determinada finalidade. Observamos três elementos das regras técnicas: ação, finalidade e a relação entre estes dois. Propomos uma classificação para as regras técnicas, de acordo com a finalidade pretendida. Teríamos as regras técnicas fáticas, conceituais e normativas. Cada uma com as respectivas finalidades: produzir um efeito no mundo, estabelecer a relação entre dois conceitos e cumprir determinada ordem ou norma. As regras técnicas fáticas e normativas pareceram interessantes para tratar do fenômeno jurídico e da função da dogmática jurídica de responder perguntas "como".

3.2 Mesmo que poucas vezes tenha sido tratada diretamente, vimos que as regras técnicas não são novidades, na teoria do direito. Autores como Ross e Schauer tratam indiretamente das regras técnicas ou percebem funções da prática jurídica semelhantes a exercida por ela. Aarnio foi o primeiro autor a tratar diretamente do tema, sugerindo as regras técnicas como proposições da dogmática jurídica. No entanto, as rejeitou. Observamos que esta rejeição trata de tentativa de tratar de temas da dogmáticaciência e dogmática-instituição, simultaneamente.

$3.3 \mathrm{O}$ discurso das regras técnicas pode ser útil para representar a função da dogmática jurídica de mediar entre linguagem das normas (prescritiva) e linguagem da realidade (descritiva). A teoria do ato administrativo é um ótimo exemplo desta função.

3.4 A figura do legislador racional foi analisada em suas características consagradas e conseguimos observar que algumas destas estão diretamente associadas à função de responder perguntas "como". Mais especificamente, com os padrões de executabilidade e proibição de lacunas normativas, vimos que, mais que acidentes históricos, alguns atributos do legislador racional são condições necessárias ao sucesso de respostas a perguntas "como".

3.5 Ao fim, estudamos a possibilidade de as regras técnicas cumprirem a função da dogmática de responder perguntas "como", sem violar a proposta positivista. Vimos que esta questão trataria de outros temas atinentes à avaliação das respostas da dogmática, não somente as condições de sucesso da resposta. Sugerimos argumentos fundamentados em estudos linguísticos acerca das detached statements. Nestes estudos, observamos a necessidade de algum tipo de marcação que indique não haver a adesão ao preceito enunciado (cancelamento de implicaturas). Concluímos haver esta marcação nas regras técnicas, que as tornaria aptas a distinguir o Censor do Expositor. 


\subsection{Reducionismo, antirredionismo e diferentes perguntas à dogmática jurídica}

Quando Kelsen e Hart enfrentaram a questão da normatividade como elemento relevante para se tratar do fenômeno jurídico, eles se colocaram diante de uma questão não tão simples de se harmonizar com as teses positivistas das fontes sociais do direito, e da separação do direito da moral. Uma das razões desta dificuldade reside nos reflexos não só para debates conceituais sobre o direito, mas sobre a própria função da dogmática jurídica (especialmente, a dogmática-ciência). Não por outra razão, Kelsen procurou com sua TPD representar uma ciência normativa do direito.

Um destes reflexos reside nos tipos de respostas que a dogmática jurídica estaria apta a responder. Ao longo do trabalho, observamos a possibilidade de ao menos duas perguntas da dogmática jurídica, cada uma com sua finalidade específica. As respostas "como", a despeito de não indicarem vinculação moral, apresentam ações, suprindo uma função prática. Teríamos, portanto, uma resposta normativa em certo sentido.

As regras técnicas são instrumentos teóricos úteis para tratar desta função de responder perguntas "como" e podem nos auxiliar na incorporação do antirreducionismo, no nível metodológico da ciência do direito, sem, contudo, tratar necessariamente de um engajamento moral. Assim, enunciados da dogmática podem tratar de perguntas práticas. Seria mantida, portanto, a distinção entre Censor e Expositor.

No entanto, uma possível pergunta que se coloca é sobre a adequação de tal tipo de norma para se especificar a função de uma dogmática-ciência. Afinal, tradicionalmente, proposições das ciências possuem a finalidade de ampliar conhecimento e não indicar ações corretas. Esta objeção cai quando nos atentamos para detalhes da dinâmica pergunta e resposta.

Como expusemos, toda pergunta é uma demanda por informacão. Estaríamos, portanto, ampliando o conhecimento. No entanto, este conhecimento possui como finalidade específica a ação e não a descrição/identificação de um objeto. Por esta razão, haveria o cumprimento de uma finalidade tradicional do conhecimento científico.

Neste aspecto, este estudo indica que os diferentes vieses positivistas, reducionista e antirreducionista, demandam diferentes funções de uma dogmática jurídica, representadas por distintas perguntas e respostas. 


\subsection{O sucesso das respostas "qual" e "como": a necessidade compreender cada peculiaridade}

Como vimos no capítulo III, é possível, a partir da apresentação de uma necessidade prática, inferir a existência de um ordenamento, o qual pode ser descrito. Haveria, então, a possibilidade de uma proposição normativa. Retornamos, portanto, a questão sugerida no capítulo 1.2 se haveria diferença no tipo de resposta.

Agora, ao final, podemos ver com mais clareza a diferença entre os tipos de respostas. Retomemos um exemplo anterior, o fundamentado na seguinte formulação: “"Ao comprador é permitido ficar com o bem se a aquisição se deu de boa fé e por título oneroso.”.

Diante desta sentença, podemos estabelecer dois tipos de perguntas correlatas: "Qual norma trata da manutenção do bem pelo comprador no caso de aquisição de boa-fé e a título gratuito?" e "Como se cumpre o direito, quando o comprador adquire o bem de boa-fé e a título gratuito?".

A primeira pergunta pode ser respondida da seguinte forma: "Não há norma que trata desta hipótese específica.” Já a segunda para ser respondida deve apresentar alguma necessidade prática que permita o cumprimento do direito. Nesta situação, há uma exigência maior para o jurista encontrar ações ou reformulações dos enunciados do ordenamento para que seja possível responder esta pergunta. No caso, poderíamos responder "Para cumprir o ordenamento, o comprador deve devolver o bem.", sem que haja qualquer dispositivo neste sentido.

Assim, observamos que a completude das perguntas "qual" e "como" não coincidem, não sendo simples a correlação entre os dois tipos de respostas. No entanto, poderíamos incorporar a noção de completude normativa nas perguntas "qual", para se fazer este paralelo?

Esta pergunta está diretamente associada à questão da relação entre lógica das normas e lógica das proposições normativas. Alchourrón deu uma resposta afirmativa a esta pergunta ${ }^{170}$. No entanto, quando vimos a tentativa de Kelsen de tratar da consistência

\footnotetext{
${ }^{170}$ Segundo Alchourrón, seria possível, por meio de assunção da completude e consistência normativas das proposições que descrevem normas, estabelecer uma correlação entre estes dois sistemas (sistemas das normas e sistema das proposições normativas. Assim, caso entendamos ser proibido haver normas contraditórias ou ausência de ação regulada, o sistema de proposições normativas e das normas mesmas serão correspondentes (ALCHOURRÓN, CARLOS E. Logica de normas y logica de proposiciones normativas.
} 
normativa (ausência de contradição), percebemos quão complexa pode ser a mera incorporação dos padrões normativos a uma linguagem descritiva, no âmbito de uma teoria do direito.

Um aspecto relevante desta complexidade reside no tipo de comprometimento das proposições descritivas da ciência do direito com a tese das fontes sociais. Em um grau mais forte e aceito por Kelsen, só pode haver alguma proposição sobre existência de normas, na ocasião de encontrarmos uma fonte social (autoridade) a quem se possa imputar este ato de vontade. Neste limite, proposições sobre o direito, mais que responder sobre normas, descrevem atos de autoridade, possuindo pouca distinção de um descritivismo reducionista. Este comprometimento é percebido na obra kelseniana de forma clara, e talvez, por esta razão, Bulygin não tem dúvidas da adesão de Kelsen às proposições normativas.

Nesta dissertação, conseguimos observar que os padrões práticos (normativos) de sucesso das respostas precisam ser dissociados dos padrões descritivos, para serem bem compreendidos e representados. Mais do que isso, são necessários para se compreender as diversas funções da dogmática jurídica.

\subsection{Ciências normativas: dos conjuntos de normas ao sistema normativo}

O tema da normatividade da ciência do direito (dogmática-ciência), para os positivistas, é uma questão sensível, que ataca o próprio centro das suas principais teses: a proposta metodológica de distinção entre Censor e Expositor. Afinal, parece um contrassenso dar um caráter normativo a uma ciência avessa a avaliações morais.

Ao longo da dissertação, percebemos que as respostas "qual" e "como", dentro das funções exercidas pela dogmática jurídica, lidam diretamente com normas de direito, mas o fazem de formas distintas. Desta forma, poderíamos dizer que representam funções distintas que podem estar associadas a diferentes sentidos de normatividade da dogmática jurídica. Para compreender a distinção presente nestes dois tipos de respostas e de sentido

Alchourrón, Carlos E.; Bulygin, Eugenio. Analisis logico y derecho. Madri: Centro de Estudios Constitucionales 1991 p. 25-51, p. 25-51.). Para uma discussão mais detalhada deste assunto, vide (NAVARRO, P. E; RODRIGUEZ, JORGE LUIZ. Deontic Logic and Legal Systems, New York, Cambridge University Press, 2014, página 85 e ss.) 
de ciência normativa, valemo-nos da distinção elaborada por Wróblewski, em Normativity of Legal Science ${ }^{171}$.

Wróblewski nos fala de quatro sentidos, em que podemos falar de uma normatividade da ciência jurídica. No presente trabalho, interessa-nos três destes $\operatorname{sentidos}^{172}$. O primeiro trata da normatividade em razão de produzir normas, isto é, a ciência do direito é considerada normativa por ter como proposição normas. O segundo sentido trata da normatividade enquanto capacidade avaliativa do direito, seria a "censorial jurisprudence". A ciência do direito, neste sentido, refere-se a norma ("a science about norm”), no entanto, há uma comparação e hierarquização de normas. O terceiro sentido da normatividade diz respeito à descrição de normas, constituindo a ciência do direito em expressões sobre normas, em seu aspecto descritivo.

Para tratar do primeiro sentido da normatividade teríamos normas mesmas, cujo objeto seriam ações. Assim, a ciência do direito, por meio de normas, indica ações necessárias ao cumprimento do ordenamento. Para tratar dos segundo e terceiros sentidos, temos proposições sobre normas. Contudo, no segundo sentido, estas proposições tratam da relação entre normas, daí a avaliação. Já o terceiro trata da descrição da existência de normas.

Destes diferentes tipos de proposições, podemos notar que as normas e suas relações aparecem como objeto nos segundo e terceiro sentido de ciência normativa. Estas, por sua vez, podem ser vistas como respostas "qual", que podem ser um tipo de resposta da dogmática jurídica. Assim, quando estamos tratando desta função específica da dogmática, estamos diante de uma ciência normativa enquanto descritiva de um conjunto de normas (segundo sentido).

Agora, quando falamos do primeiro sentido, a normatividade da ciência surge como condição de seu próprio sucesso. Da mesma forma, a resposta "como" demanda a incorporação de "padrões normativos" para que a dogmática jurídica consiga exercer esta função. Assim se dá porque estamos diante da função de orientar ações, somente no primeiro sentido de ciência normativa. Por conseguinte, a dogmática jurídica quando executa esta função específica ganha os contornos de sistema normativo. Neste caso, a

\footnotetext{
${ }^{171}$ WRÓBLEWSKI, JERZY. “Normativity of Legal Science”, Logique et Analyse, pp. 60-77, 1966.

${ }^{172} \mathrm{O}$ quarto sentido de ciência normativa explorada por Wróblewski trata da concepção filosófica de que objetos culturais, tal qual o direito, precisam de uma metodologia própria, distinta das ciências descritivas. No âmbito da teoria do direito, exemplo da aplicação deste tipo de concepção está presente na teoria egológica do direito de Cossio. (WRÓBLEWSKI, JERZY. "Normativity of Legal Science", Logique et Analyse, pp. 60-77, 1966, p. 66-8.)
} 
dogmática jurídica deixa de ter como finalidade única a representação de um conjunto de normas do direito para se tornar ela própria um sistema normativo. Para compreender como o sistema normativo é tratado neste trabalho, valemo-nos do conceito de sistema normativo de Alchourrón e Bulyigin.

Alchourrón e Bulygin, em seu Normative Systems, procuraram, a partir de preceitos formais, estabelecer conceitos elementares de um sistema normativo, definindo-o e caracterizando-o. Inicialmente, investigam uma atividade da ciência do direito: a de relacionar casos a soluções normativas. Para os efeitos deste trabalho, é importante notar que soluções normativas são indicações de ações devidas (obrigatórias). Assim, uma das funções da ciência do direito seria a sistematização destas relações entre casos e soluções normativas.

A partir desta perspectiva, sistemas normativos podem ser definidos como conjunto de sentenças os quais possuem todas as consequências normativas virtualmente inferidas a partir de sentenças jurídicas ${ }^{173}$. Por se tratar de consequências normativas, tal sistema teria como ideal tanto a coerência como a completude normativas e não as descritivas. Tais sistemas normativos, contudo, possuem como pressuposto um problema normativo, que trata da pergunta sobre a qualificação normativa de determinada ação.

Tais sistemas normativos, na acepção de Alchourrón e Bulygin, exerceriam funções semelhantes às respostas "como" e, consequentemente, às regras técnicas. Afinal, tanto as respostas "como" e estas soluções normativas respondem como alguém precisa agir para se cumprir o direito. Assim, os sistemas normativos, vistos usualmente como objetos da ciência do direito, seriam, a bem da verdade, constitutivos de uma função específica da dogmática jurídica.

Conclui-se que o sentido de ciência normativa que possui como objetos normas, está diretamente associado à função de responder perguntas “qual”, já o sentido de emanar normas está diretamente associado às perguntas "como". Somente neste último sentido, a dogmática jurídica pode ser vista como um sistema normativo. No sentido de responder perguntas “qual”, o que temos é um conjunto de normas.

\subsection{Limitações desta dissertação, trabalhos futuros e as marcas da dogmática}

\footnotetext{
173 "Um conjunto normativo es un conjunto de enunciados tales que entre suss consequências hay enunciados que correlacionan casos com soluciones. Todo conjunto normativo que contiene todas sus consequências es, pues, um sistema normativo" (ALCHOURRÓN, CARLOS; e BULYGIN, EUGENIO. Introducción a la metodología de las ciencias jurídicas y sociales, Buenos Aires : Editorial Astrea de R. Depalma, 1975, p. 92)
} 
Ao longo desta dissertação conseguimos realizar uma primeira aproximação da função exercida pela regra técnica e sua capacidade de representar uma função específica da dogmática jurídica. Também nos aproximamos da repercussão sobre a teoria positivista, especialmente na capacidade de lidar com a distinção entre reducionismo e antirreducionismo, bem como podemos compreender melhor em que sentido uma ciência do direito pode ser chamada de normativa. Contudo, muitos outros temas devem ser explorados para se compreender melhor as possíveis repercussões das regras técnicas para uma teoria positivista.

Como já informado na Introdução, preferimos tratar mais das condições de sucesso das respostas do que da relação ou escolha dentre possíveis respostas. Por esta razão, temas como fundamento da interpretação, soluções de controvérsias teóricas e exploração mais aprofundada das teses positivistas foram deixados de lado. No entanto, estes temas devem ser mais bem explorados em investigações futuras para se compreender o reflexo das regras técnicas para uma teoria do direito positivista. Em especial, a compreensão da teoria das fontes e seu real significado devem ser associados com a capacidade das regras técnicas de serem verdadeiras ou falsas.

Por fim, para além da finalidade acadêmica desta dissertação, acredito que a pergunta sobre quais marcas a dogmática pode deixar em nós, os profissionais do direito, permeou o presente trabalho e, mesmo que estejamos longe de compreendê-la, estamos mais próximos de aceitar que esta investigação requer a compreensão das diversas funções da dogmática jurídica, em seu sentido científico ou histórico. E, mais importante que entendermos as respostas que damos com as dogmáticas é ouvir as perguntas que pressupomos quando trabalhamos com o direito, para podermos ver as marcas que ele deixa em nós. 


\section{BIBLIOGRAFIA}

AARNIO, A. On legal reasoning. Turku: Turun Yliopisto., 1977.

AARNIO, A. The rational as reasonable, D. Reidel Publishing Company 1987

ALCHOURRÓN, CARLOS E. Logica de normas y logica de proposiciones normativas. Alchourrón, Carlos E.; Bulygin, Eugenio. Analisis logico y derecho. Madri: Centro de Estudios Constitucionales 1991 p. 25-51.

ALCHOURRÓN, CARLOS E. "On Law and Logic”, in Beltran, Jordi; e Ratii, Giovanni (eds). The logic of legal requirements, Essays on defeasibility. Oxford Press, 2012 (artigo originalmente publicado em 1996) p. 39-53.

ALCHOURRÓN, CARLOS; e BULYGIN, EUGENIO. Introducción a la metodología de las ciencias jurídicas y sociales, Buenos Aires : Editorial Astrea de R. Depalma, 1975.

Alchourrón, Carlos E.; Bulygin, Eugenio. "Fundamentos Pragmaticos para uma logica de normas”. Alchourrón, Carlos E.; Bulygin, Eugenio. Analis logico y derecho. Madri: Centro de Estudios Constitucionales 1991.

ALCHOURRÓN, CARLOS; BULYGIN, EUGENIO. Sobre la existência de las normas jurídicas, Primeira Edição, Distribuciones Fontamar: Mexico DF, 1997.

ALEXY, ROBERT. Teoria da argumentação juridical - a A teoria do discurso racional como teoria da justificação jurídica. Tradução: Zilda Hutchinson Schild Silva. Revisão: Claudia Toledo. São Paulo: Landy. 2005.

ALEXY, ROBERT; BULYGIN, EUGENIO. La pretension de correccion del derecho: La polémica sobre la relacion entre derecho y moral, Tradução: Paula Gaido. Colombia: Universidad Externado de Colombia - Série de Teoria Jurídica y Filosofia del derecho, n. 18. 
AQVIST, LENNART. Introduction to deontic logic and the theory of normatize systems. Napoli: Bibliopolis, 1987.

ATRIA, FERNANDO, Del Derecho y el Razonamiento Juridico, em Doxa n. 25, 1999, p 79-119.

BELNAP, N. D. The Logic of Questions and Answers, Yale University Press, New Haven, 1976.

BENTHAM, JEREMY. An introduction to the Principles of Morals and Legislation, Batoche Books, 2000.

BOBBIO, NOBERTO. "Sein" and "Sollen” in the legal Science' in Archiv für Rechts und Sozialphilosophie LVI, nº 6, pp 7-30, 1970, presente em coletânea Jori, Mario. Legal Positivism. The International Library of Essays in Law \& Legal Theory,New York, New York Press reference collection, 1992, pp 329-353.

BIX, BRIAN H. "Defeasibility and Open Texture". The logic of legal requirements: Essays on Defeasibility. Editores Jordi Ferrer Beltrán e Giovanni Battista Ratti. Oxford. Oxford Print, 2012, pp. 193-201

BOBBIO, NORBERTO. O Positivismo Jurídico, $1^{\circ}$ Edição, São Paulo: Ícone, 1995.

BULYGIN, EUGENIO. "Normas, proposiciones normativas y enunciados jurídicos” in ALCHOURRÓn, CARLOS E.; BULYGIN, EUGENIO. Analisis logico y derecho. Madri: Centro de Estudios Constitucionales 1991, p. 169-195.

BULYGIN, EUGENIO. "Sobre la regla de reconocimiento", in ALCHOURRÓN, CARLOS E.; BULYGIN, EUGENIO. Analisis logico y derecho. Madri: Centro de Estudios Constitucionales 1991, p. 383-393.

BULYGIN, EUGENIO. "Enunciados jurídicos y Positivismo: respuesta a Raz”, in ALCHOURRÓN, CARLOS E.; BULYGIN, EUGENIO. Analisis logico y derecho. Madri: Centro de Estudios Constitucionales 1991, p. 427-438. 
BULYGIN, EUGENIO. "True or False Statements in Normative Discourse", em "In search of a New Humanism: The philosophy of Georg Henrik von Wright. Edited by Rosaria Egidi.. Synthese Library Studies In Epistemology, Logic, Methodology, And Philosophy Of Science, Vol. 282, Springer, 1999, pp. 183-192.

BUlygin, EUGENIO. En defensa de El Dorado. Respuesta a Fernando Atria, in Atria et Alii. Lagunas en Derecho. Madri: Marcial Pons, 2005.

BULYGIN, EUGENIO; MENDONÇA, DANIEL. Normas y Sistemas Normativos, Madrid-Barcelona. Editora Marcial Pons. 2005.

BUSTAMANTE, THOMAS. “A breve história do positivismo descritivo. O que resta do positivismo jurídico depois de H. L. A. Hart?” em Revista Novos Estudos Jurídicos Eletrônica, Vol. 20 - n. 1 - jan-abr 2015, pp. 307-327.

CABRERA, CARLOS ALARCÓN. Imperativos y lógica em Jørgensen, Isegoria $\mathrm{n}^{\circ} 20$, 1999, pp. 207/215.

CARACCIOLO, RICARDO. El concepto de laguna. Descripcion o Prescripcion em La noción de sistema em la teoria del derecho, Mexico: Fontanamara, 27-36.

CHIASSONI, PIERLUIGI. O enfoque analítico na filosofia do direito: de Benthan a Kelsen. Tradutores: Heleno Taveiras Torres e Henrique Mello. São Paulo. Editora Contracorrente, 2017.

COMANDUCCI, PAOLO. “La interpretacion jurídica.” Beltrán, J. F.; Ratti, G.B (eds.). El realismo jurídico genovês, Marcial Pons, Madrid, 2011, p. 51-69.

DAVID, RENÉ. Grandes sistemas do direito contemporâneo: direito comparado, 2. ed. Lisboa: Meridiano, 1978.

D’ALMEIDA, LUÍS DUARTE. "Legal Statements And Normative Language”. Law and Philosophy, Vol. 30, nº 2, Springer, 2011. 
DI PIETRO, MARIA SYLVIA ZANELLA. Direito Administrativo, 24a Edição. 2011.

DWORKIN, RONALD. Law's Empire, Harvard University Press 1986.

DWORKIN, RONALD. Legal Theory and the problem of sense. In: GAVISON, R. (Ed.). Issues in encyclopedia of philosophy. 2003.

DUNAWAY, B, SILK, ALEX. “Whiter Anankastics?” in Philosophical Perspectives, 28, Ehics, 2014.

EBENSTEIN, WILliAn. La teoria Pura del Derecho. México - Buenos Aires : Fondo de Cultura Econômica, 1947.

FERRAZ JÚNIOR, TÉRCIO SAMPAIO. A ciência do direito, 1a. ed. São Paulo: Editora Atlas, 1977.

FERRAZ JÚNIOR, TÉRCIO SAMPAIO. Introdução ao estudo do direito : técnica,

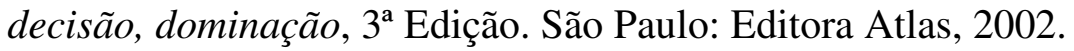

GAMUT, L. T. F. Logic, language and meanin, v. 1. Chicago, The University of Chicago Press, 1991.

GUASTINI, RICCARDO. Sollsätze. An Exercise in Hard Legal Positivism, in Rechtstheorie, vol. 31, 2000.

GUASTINI, RICCARDO. “Contribución a la teoria del ordenamento jurídico”, Ferrer, Jordi; Ratti, Giovanni. El realismo jurídico genovêsEditora Marcial Pons, 2011.

GUASTINI, RICCARDO. Defeasibility, Axiological Gaps, and Interpretation, in FERRER, JORDI; E RATII, GIOVANNI (eds). The logic of legal requirements, Essays on defeasibility, Oxford Press, 2012. P. 182-192. 
GILISEN, JOHN. Introdução Histórica ao Direito, Tradução Antonio Manuel Hespanha. Lisboa. Fundação Calouste Gulbenkian. 2001.

HART, H. L. A. Problems of the Philosophy of Law, em Essays in Jurisprudence and Philosophy. Oxford: Clarendon Press. 1983.

HART, H.L.A. "O Positivismo e a separação entre o Direito e a Moral". Ensaios sobre Teoria do Direito e Filosofia. Tradução José Garcez Ghirardi e Lenita Marai Rimoli Esteves. Revisão Técnica: Ronaldo Porto Macedo e Leonardo Gomes Penteado Rosa. Rio de Janeiro: Editora Elsevier, 2010.

HART, H.L.A. “Kelsen Visitado”. Ensaios sobre Teoria do Direito e Filosofia. Tradução José Garcez Ghirardi e Lenita Marai Rimoli Esteves. Revisão Técnica: Ronaldo Porto Macedo e Leonardo Gomes Penteado Rosa. Rio de Janeiro, Elsevier, 2010.

HART, H. L.A. O conceito de Direito, pós-escrito organizado por: Penelope A. Bulloch e Joseph Raz ; tradução de: Antônio de Oliveira Sette-Câmara ; revisão de tradução: Marcelo Brandão Cipolla ; revisão técnica: Luiz Vergílio Dalla-Rosa. -- São Paulo, Martins Fontes, 2009.

HILPINEN, RISTO; FOLLESDAL, DAGFIN. Deontic Logic: na introduction. Hilpinen, Risto (ed.) Deontic Logic: Introctory and Systematic Reading. Reidel Publishing Company, 1971, p. 1-36.

HILPINEN, RISTO; MCNAMARA, PAUL. Deontic Logic: a historical survey and introduction. Gabbay, Dov et alii (editores) Handbook of Deontic Logic and Normative Systems. College Publications, 2013, p.3-137.

HINTIKKA, JAAKO. Some Main Problems of Deontic Logic. HILPINEN, RISTO (ed.) Deontic Logic: Introctory and Systematic Reading. Reidel Publishing Company, 1971, p. 59-104.

JØRGENSEN, JORGEN, “Imperativer og Logik”, Theoria, núm. 4, 1938, pp. 183-190 
JØRGENSEN, JORGEN. “Imperatives and Logic”. Erkenntnis 7, 1939, pp. 288-296.

KANGER, STIG. New Foundations for Ethical Theory. HILPINEN, RISTO (ed.) Deontic Logic: Introctory and Systematic Reading. Reidel Publishing Company, 1971, p. 36-58.

KELSEN, HANS. Teoria pura do direito, 6. ed. 4.tiragem, edição original, 1960 São Paulo: Martins Fontes, 2000.

KELSEN, HANS. Teoria geral das normas, Edição original 1970, Porto Alegre : Fabris, 1986.

LUPKOWSKI, PAWET. Logic of question in the wild - Inferential Erotetic Logic in information seeking Dialogue Modelling. GABBAY, DOV (ed.) Studies in Logic, vol 64, 2015 .

KNUUTTILA S. The Emergence of Deontic Logic in the Fourteenth Century. In: HILPINEN R. (eds) New Studies in Deontic Logic, Synthese Library (Studies in Epistemology, Logic, Methodology, and Philosophy of Science), vol 152. Springer, Dordrecht. 1981

MACCORNICK, NEIL. Argumentação jurídica e teoria do direito, Trad. Barcellos, Waldea. Revisão: Michael, Marylene. São Paulo: Martins Fontes, 2006.

MARMOR, ANDREI. Interpretation and legal theory. Second Edition. Hart Publishing. Oxford and Oregon, 2005.

MARANHÃO, JULIANO. Padrões de racionalidade na sistematização de normas, Tese de Doutorado defendida para obtenção de grau de Doutor, junto à Faculdade de Direito da Universidade São Paulo, em 2004.

MARANHÃO, JULIANO. Lógica e Ontologia das Normas Jurídicas. Revista Brasileira de Filosofia, v. 233, p. 7-36, 2009. 
MARANHÃO, JULIANO. Positivismo jurídico lógico-inclusivo, São Paulo: Marcial Pons, 2012.

MARANHÃO, JULIANO. Estudos sobre Lógica e Direito, São Paulo, Marcial Pons, 2013.

MARANHÃO, JULIANO. Critical Remarks on Ratti's 'five faces of the incompleteness of law', Revista Brasileira de Filosofia, v. 240, 2013, p. 144-158,.

MARANHÃO, JULIANO. La lógica de implicación normativa de von Wright y la paradoja de Chisholm, DOXA (ALICANTE), v. 1, p. 65-84, 2016.

MAZZARESE, TECLA. "Norm Proposition": A Tentative Defense of a Sceptical View", em In search of a New Humanism: The philosophy of Georg Henrik von Wright. Edited by Rosaria Egidi.. Synthese Library Studies In Epistemology, Logic, Methodology, And Philosophy Of Science, Vol. 282, Springer, 1999.

MICHELON JR, CLAUDIO FORTUNATO. Aceitação e objetividade: uma comparação entre as teses de Hart e do positivismo precedente sobre a linguagem e o conhecimento do direito, São Paulo: Revista Dos Tribunais, 2004.

MORESO, JOSÉ. Legal Positivism and Legal Disagreements. Ratio Juris, 22, março, 2009.

MULLINS, ROBERT. "Detachment and Deontic Language in Law", in Law and Philosophy vol 37: Springer Science, 2018, pp. 351-384., p. 371.

NAVARRO, P., AND MORESO, J. J., Normas permissivas, sistemas jurídicos y clausura normativa: Um anáises de la evolucion de las ideas de Carlos alcourron y Eugenio Bulygin in Theoria: na international jornal for theory, History and Foudnations of Science, Segunda Época ,vol 7. № 16/18 número especial.

NAVARRO, P. E; RODRIGUEZ, JORGE LUIS. Deontic Logic and Legal Systems, New York, Cambridge University Press, 2014. 
NINO, CARLOS SANTIAGO. Algunos modelos metodológicos de ciência” jurídica, Primeira Edição, quarta impressão, Ediciones Fontamara, México, DF, 2007.

NINO, CARLOS SANTIAGO. El Concepto de validez jurídica em la teoria pura de Kelsen, In: La validez del Derecho, Coleccion Mayor Filosofia Y Derecho, Buenos Aires: Astrea, 1985.

NINO, CARLOS SANTIAGO. Algunos modelos metodológicos de "ciência" jurídica, Primeira Edição, quarta impressão. México, DF, 2007.

NINO, CARLOS SANTIAGO. Introdução à análise do direito, Tradução Elza Maria Gasparotto; revisão da tradução Denise Matos Marino. São Paulo, Editora Martins Fontes, 2010.

PAULSON, STANLEY. “The Great Puzzle: Kelsen's basic norm”. in Kelsen Revisited: New Essays on the Pure Theory of law. Editado por Eduardo Duarte d'Almeida, John Gardner e Leslie Green. Portland. Hart Publishing, 2013.

PAULSON, STANLEY. "The Neo-Kantian Dimension of Kelsen's Pure Theory of Law" Oxford Journal of Legal Studies, Vol. 12, No. 3, 1992

PAULSON, STANLEY. “Hans Kelsen's Doctrine of Imputation”. Ratio Juris. Vol. 14 No. 1 March 2001.

PERELMAN, CHAIN. Tratado de argumentação: a nova retórica, tradução Maria Ermantina de Almeida Prado Galvão [revisão da tradução Eduardo Bradão] 2a edição São Paulo: Martins Fontes, 2005.

RATTI, G. B., RODRÍGUEZ, JORGE LUIS. On Coherence as a Formal Property of Normative Systems, Revus, 2015, p. 131-146.

RATTI, GIOVANNI BATTISTA. Contemporary Jurisprudence through Genoese Eyes, Texto inédito apresentado em reunião do grupo Pós-Debate, em São Paulo - SP, em 09 de novembro de 2016, autorização de uso pelo próprio autor. 
RAZ, JOSEPH. Ethics in the public domain: essays in the morality of law and politics. Oxford University Press, 2001.

RAZ, JOSEPH. "The purity of the Pure Theory of Law”. Essays on Kelsen. Editore: R. TUR e W. Twining. Oxford. Oxford University Press, 1986.

RODRIGUEZ, JORGE LUIS. "Lagunas axiológicas y relevância normativa”, em Doxa Cuadernos de Filosofía del Derecho, n 22, 2000, p. 349-369.

RODRIGUEZ, JORGE LUIS. "Kelsen y la verdade de los enunciados jurídicos". Laura Clérico y Jan -R Sieckmann (eds.), La teoría del derecho de Hans Kelsen, Bogotá, Universidad Externado de Colombia, 2011, p. 73-112.

RODRIGUEZ, JORGE LUIS. “Norms, Truth, and Legal Statements”. Jordi Ferrer Beltran Jose Juan Moreso y Diego Papayanis (eds.), Neutrality in Theory of Law. Editora: The Netherlands, Sprnger, 2013, p. 127-146.

ROSS, ALF. Imperatives and Logic, Theoria 7. 1941, p. 53-71.

ROSS, ALF, "Validity and the conflict between legal positvism and Natural Law", Revista Juridica de Buenos Aires, 1961. pp. 46-93.

ROSS, ALF. Lógica de las normas, Madrid : Editroial Tecnos, 1971.

ROSS, ALF. Direito e Justiça, $2^{\mathrm{a}}$ ed. Tradução e notas de Edson Bini, revisão técnica Alysson Leandro Mascaro. Bauru, EDIPRO, 2007.

SCHAUER, FREDERICK. Playing by the rules: A philosophical examination of rulebased decision-making in the law and in life, Oxford: Clarendon Press, 2002.

TUZET, GIOVANNI. “Describir Normas: um enfoque pragmático”, DOXA, Cuadernos de Filosofía del Derecho, 41 (2018). 
VAQUERO, ÁLVARO NÚÑEZ. “Five Models of Legal Science”, Revus [Online], 19 2013, Online since 31 May 2013, acessada em 19 de abril de 2019. URL : http://journals.openedition.org/revus/2449 ; DOI : 10.4000/ evus.2449.

VAQUERO, ÁLVARO NÚÑEZ. “Ciencia jurídica realista: modelos y justificación”. DOXA, Cuadernos de Filosofía del Derecho, 35, 2012, pp. 717-747.

VON WRIGHT, GEOG HENRIK. Deontic Logic. Mind 60, 1951, p. 1-15.

VON WRIGHT, GEORG HENRIK. Pratical Inference, in The Philosophical Review, Vol. 72, No. 2 (Apr., 1963), pp. 159-179.

VON WRIGHT, GEORG HENRIK. Norma y accion: una analise lógica, Madrid : Tecnos, 1970.

VON WRIGHT, GEORGE HENRIK. “A New System of Deontic Logic”. HILPINEN, RISTO (ed.) Deontic Logic: Introductory and Systematic Readings. Dodrecht Holand Reidel Publishing Company, 1971a.

VON WRIGHT, GEORGE HENRIK. "Deontic Logic and the Theory of Conditions", in Hilpinen, Risto (ed.) Deontic Logic: Introductory and Systematic Readings. Dodrecht Holand Reidel Publishing Company, 1971b.

VON WRIGHT, GEORGE HENRIK. "Norms, Truth and Logic, in Practical Reason. Philosophical Papers, vol. 1, Oxford: Basil Blackwell, 1983. p. 130-209.

VON WRIGHT, GEORGE HENRIK. Deontic logic: a personal view, Ratio Juris, March, 1999, Vol.12(1), p.26-38.

WISNIEWSKI, ANDRZEJ. The Posing of questions - Logical Foundations of Erotetica Inferences. Studies in Epistemology, Logic Methodology, and Philosophy of Science, vol $252,1995$. 
WISNIEWSKI, ANDRZEJ. Questions, Inferences, and Scenarios, London: College Publications, 2013.

WRÓBLEWSKI, JERZY. “Normativity of Legal Science”, Logique et Analyse, pp. 60-77, 1966 